\title{
Modelos de comunicação e uso de impressos na educação em saúde: uma pesquisa bibliográicica"
}

Fernanda Valéria de Freitas ${ }^{1}$ Luiz Augusto Rezende Filho ${ }^{2}$

FREITAS, F.V.; REZENDE FILHO, L.A. Communication models and use of printed materials in healthcare education: a bibliographic survey. Interface - Comunic., Saude, Educ., v.15, n.36, p.243-55, jan./mar. 2011.

This paper presents the results from a bibliographic survey on the use of printed materials in healthcare education. The focus was on communication models, users' representations and the dynamics of content selection and assessment. An analysis was conducted on 11 articles surveyed in the Scielo database. In this analysis, the articles indicated that the communication was characterized by a linear model and impersonality. The receivers were considered to be mere consumers of scientific concepts. In most cases, health professionals were the only people responsible for the selection of content. In the articles surveyed, a conflict between their authors' perspective (dialogical) and the printed materials producers' perspective (unilinear) can be found.

Keywords: Health education.

Communication. Models of communication. Representations. Educational and promotional materials. Printed material.
$\mathrm{O}$ artigo apresenta os resultados de uma pesquisa bibliográfica sobre o uso de materiais impressos na educação em saúde, enfocando os modelos de comunicação, as representações dos usuários e as dinâmicas da seleção de conteúdos e de avaliação. Realizou-se uma análise de 11 artigos pesquisados a partir da base Scielo. Nessa análise, os artigos apontam que a comunicação se caracteriza predominantemente pelo modelo unilinear e pela impessoalidade. Os receptores são considerados meros consumidores de conceitos científicos. Na maioria das vezes, os profissionais de saúde são os únicos responsáveis pela seleção dos conteúdos. Nos artigos pesquisados pode-se encontrar um conflito entre a perspectiva dos seus autores (dialógica) e a dos produtores dos impressos (unilinear).

Palavras-chave: Educação em Saúde. Comunicação. Representações. Materiais educativos e de divulgação. Material impresso.

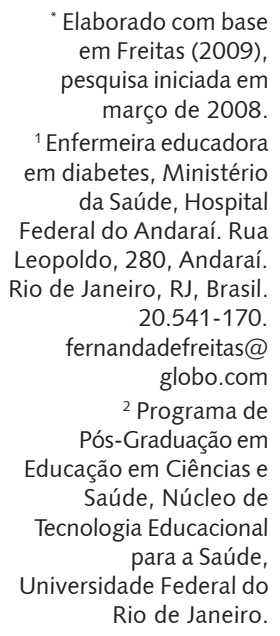

Elaborado com base em Freitas (2009), pesquisa iniciada em março de 2008. ${ }^{1}$ Enfermeira educadora em diabetes, Ministério da Saúde, Hospital Federal do Andaraí. Rua Leopoldo, 280, Andaraí. Rio de Janeiro, RJ, Brasil. 20.541-170. fernandadefreitas@ globo.com

2 Programa de Pós-Graduação em Educação em Ciências e Saúde, Núcleo de Tecnologia Educacional para a Saúde, Universidade Federal do Rio de Janeiro. 


\section{Introdução}

A necessidade de manter os pacientes informados é amplamente reconhecida e praticada nos atendimentos clínicos. Tal fato motiva a produção de materiais impressos para diversos propósitos, como: orientar e adaptar comportamentos, promover a saúde, prevenir futuros acometimentos ou informar sobre riscos e estilos saudáveis de vida. Assim, de uma forma geral, os materiais impressos usados na educação em saúde têm como objetivo divulgar conteúdos considerados importantes para a prevenção ou tratamento de enfermidades. De maneira mais específica, estes materiais informam sobre mecanismos que determinam ou favorecem estados ideais de saúde, procuram reforçar orientações transmitidas oralmente em consultas e contribuir na implementação, pelo próprio indivíduo, de cuidados necessários ao tratamento ou prevenção de doenças. Esses materiais de divulgação - nos formatos de cartazes, cartilhas, folders, panfletos, livretos - são, convencionalmente, chamados de "materiais educativos" nos serviços de saúde, por fazerem parte da mediação entre profissionais e população (Monteiro, Vargas, 2006).

O problema da pesquisa refere-se à necessidade de se conhecer o processo comunicativo por materiais educativos, tendo em vista que o uso de materiais educativos de forma adequada pode resultar em benefícios na vida do indivíduo. Sendo assim, realizamos uma pesquisa bibliográfica que procurou apresentar e discutir alguns dos problemas e características encontrados, por pesquisas brasileiras, na comunicação e educação em saúde por meio de impressos. O objeto de estudo deste artigo refere-se, portanto, ao uso de materiais impressos na educação em saúde, tendo como base a descrição e análise de pesquisas que enfocam a utilização desses materiais.

Diante do uso disseminado de materiais impressos na prática educativa e da sua importância; do entendimento dos processos de educação e comunicação em saúde como práticas sociais orientadas por questões e situações contextuais, que se traduzem em formas de ver a realidade e de construir significados (Oliveira, 2007); e do compartilhamento e negociação de sentidos, valores e motivações que caracterizam o uso, a produção e a recepção de impressos na educação em saúde (Kelly-Santos, 2009; Araújo, 2006), estabelecemos como objetivos deste trabalho: 1) identificar os modelos de comunicação presentes nos materiais impressos analisados pelos artigos pesquisados; 2 ) conhecer as representações do receptor/sujeito adotadas pelos materiais; 3 ) descrever a dinâmica de seleção do conteúdo dos materiais; 4) identificar como se dá - sempre segundo os artigos pesquisados - a avaliação da produção e/ou uso dos impressos na educação em saúde.

\section{Procedimentos metodológicos}

A pesquisa bibliográfica foi realizada no Scientific Eletronic Library Online (Scielo) em dois momentos: a primeira busca utilizou o descritor "educação em saúde", para a pesquisa inicial, combinado com unitermos; e a segunda, o descritor "impressos", para uma busca mais precisa.

Usando o primeiro descritor, realizamos um levantamento inicial totalizado em 277 artigos. Todos os resumos destes artigos foram lidos e analisados, buscando-se os unitermos: materiais didáticos; material educativo; material informativo; impressos; folhetos; cartazes; cartilhas educativas; e manuais de orientação. Esta seleção resultou num total de 21 artigos.

Desse total, foram excluídas ainda, também por meio da leitura dos resumos, as pesquisas que: utilizavam como contexto a saúde escolar; utilizavam os folhetos apenas como tipos de publicação incluída em uma revisão bibliográfica; utilizavam material informativo somente como instrumento de pesquisa com sujeitos, sem que a utilização desse material fosse o enfoque da pesquisa; apenas descreveram formalmente a produção de impressos por profissionais de saúde; e utilizaram os materiais educativos como meio de comunicação e aprendizagem em jogos educativos. Do total de 21 artigos, selecionaram-se dez artigos, que compuseram a análise deste trabalho.

Para revalidar a representatividade da pesquisa bibliográfica realizada, utilizamos, como segundo descritor, "impressos", mais específico para a temática da pesquisa. Obtiveram-se 53 artigos. Foram excluídos os trabalhos já selecionados na primeira busca e, também, após leitura dos resumos, aqueles 
que não tratavam de impressos na educação em saúde. Dos 53 artigos, apenas um contemplava os critérios de escolha descritos acima. Acrescidos dos dez artigos obtidos na primeira busca, foram analisados, no total, onze trabalhos que contemplavam os critérios desta pesquisa.

Não incluímos, na pesquisa, artigos da literatura internacional, pois se objetivou revisar a prática educativa por impressos desenvolvidos nos serviços de saúde do SUS no Brasil. O ano de publicação não foi utilizado como critério de exclusão.

A Tabela 1 lista os títulos dos artigos analisados, seus autores, o ano de publicação e o periódico em que foram publicados.

Tabela 1. Artigos analisados

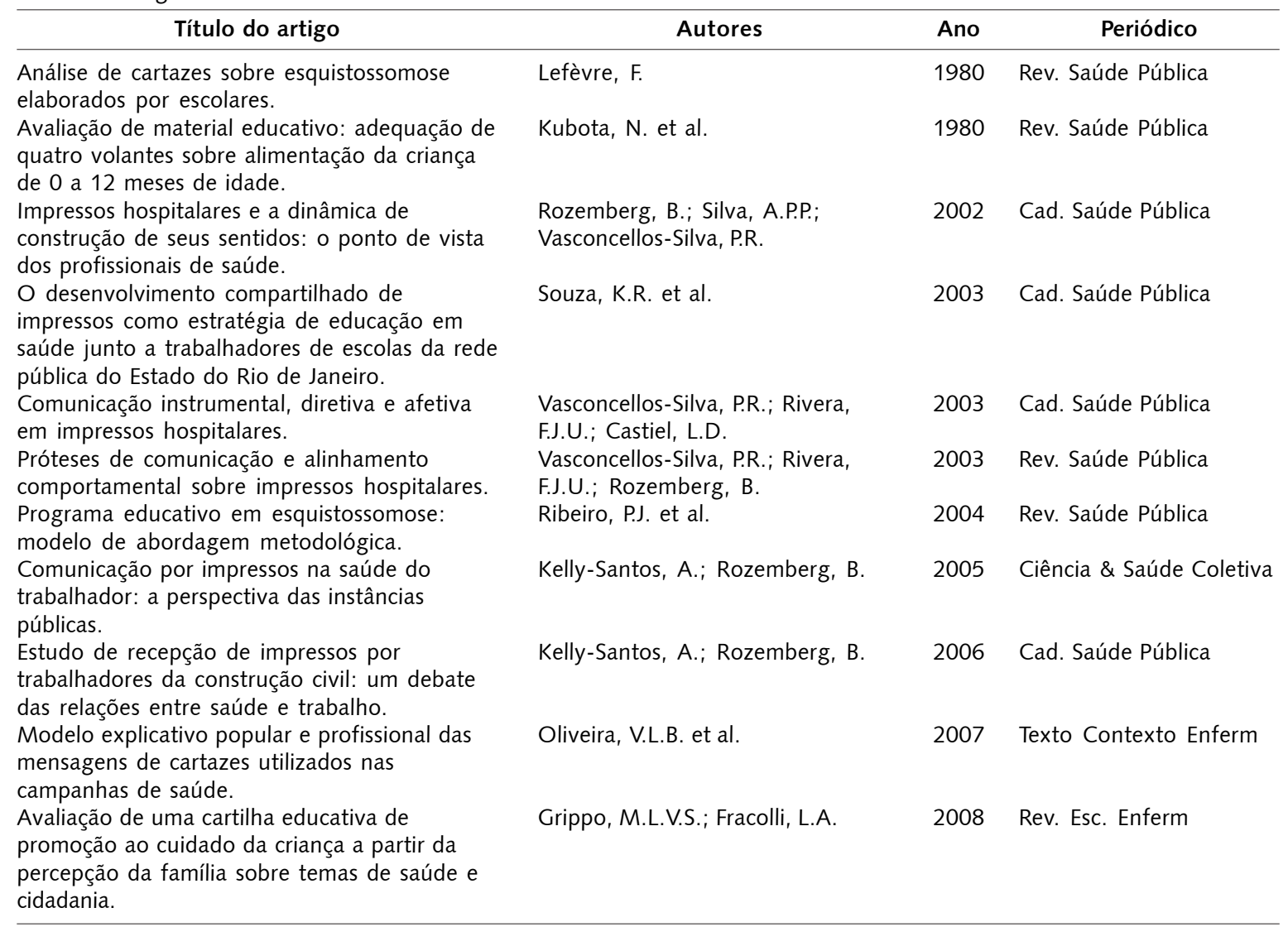

\section{Referencial de análise}

Para a discussão dos resultados encontrados serão apresentados, nesta seção, os referenciais que nortearam, de forma teórica e crítica, a análise das questões pesquisadas nos artigos. Tais referenciais dizem respeito às formas como podem ser concebidos, para este trabalho, o processo de comunicação por impressos e o papel do sujeito-receptor nesse processo.

Para a análise dos artigos, adotamos o esquema interpretativo sugerido por Teixeira (1997), sob a forma de diferentes "modelos de comunicação" que caracterizariam os impressos. Em seu artigo, o 
autor indica quatro modelos principais (unilinear, dialógico, estrutural e diagramático), dos quais faremos referência apenas aos três primeiros, já que isto nos parece atender aos objetivos deste trabalho.

O modelo unilinear se caracteriza por tomar a comunicação como, essencialmente, uma relação entre um emissor e um receptor, na qual o emissor aplica determinados estímulos e obtém, do receptor, determinadas respostas. Trata-se, fundamentalmente, de um modelo marcado pela unilinearidade, porque supõe o primado de uma direção única de comunicação (do polo emissor ao receptor), e pela causalidade de um polo sobre o outro, ou seja, as ações do emissor causam reações razoavelmente previsíveis no receptor. A comunicação seria uma consequência mecânica (efeitos) de ações de A sobre B (Fausto Neto, 1995). A este modelo corresponderia, segundo Teixeira (1997), a visão historicamente hegemônica nas práticas de comunicação/educação em saúde, pela qual o fornecimento de informações (ação do emissor) produziria mudanças de comportamento em benefício de uma vida mais saudável (resposta previsível do receptor).

Este modelo está fortemente enraizado nas práticas de saúde pública vigentes, em que se valoriza o saber médico para fomentar hábitos e práticas de promoção à saúde e a adesão da população aos procedimentos médico-sanitários. Essas ações retratam o modelo tradicionalista da saúde pública com uma perspectiva controladora e adaptativa, como uma estratégia de controle social, ditando normas de conduta moral, social e higiênica (Santos, Westphal, 1999).

No que diz respeito à comunicação por impressos como prática de educação em saúde, esta se encontra, segundo Teixeira, balizada pelo modelo unilinear e pelo "núcleo técnico fundamental" que o caracteriza. Primeiramente, supõe-se que há uma falta ou atraso a ser superado e que a superação desses se dará por meio de conhecimentos técnico-científicos. Em um segundo momento, o emissor elabora mensagens (impressos) com elementos comuns e em sintonia com o receptor, realizando uma "decodificação da retórica técnica para uma retórica popular" (Teixeira, 1997, p. 22). Essas mensagens devem se oferecer como "um 'poder organizador' do conhecimento de um outro" (Teixeira, 1997, p. 21) de forma a produzir um comportamento mais saudável que leve à superação do problema inicial. Supõe-se, portanto, que o êxito da prática educativa se fundamenta apenas, ou sobretudo, na transmissão de informações, e que o importante é informar, independente do contexto e dos indivíduos envolvidos, pois "quanto mais se dá mais se sabe" (Freire, 1994, p.3).

Os modelos dialógico e estrutural, por sua vez, são marcados pela oposição ao modelo unilinear (Teixeira, 1997). Em ambos os modelos, a educação em saúde deixa de ser um instrumento de manipulação, em um processo persuasivo para transferência de informações, e passa a ser um processo de potencialização de transformações da realidade, por meio de uma relação de diálogo, de troca, bidirecional e democrática (Assis, 1992).

Seguindo este panorama, os modelos comunicacionais questionam o modelo unilinear, seja por sua "eticidade" (modelo dialógico), seja por sua ineficiência (modelo estrutural) (Teixeira, 1997). O primeiro se filia às abordagens freireanas dos problemas da comunicação e educação em saúde, e critica a comunicação unilinear como "invasão cultural" (Freire, 1983) realizada pelo profissional de saúde ou pelo educador, ao pretender impor a sua cultura/saber sem considerar a cultura/saber do outro, e considera a ação de saúde como espaço de diálogo e negociação. Como alternativa ao modelo unilinear, o modelo dialógico propõe a "problematização" da realidade dos educandos para que estes atuem de forma crítica e autônoma sobre ela e em direção à sua transformação. Segundo Teixeira, tal modelo traz, no entanto, a dificuldade que se encontra em assumir, em profundidade, o "risco do diálogo conflitivo" e em oferecer, de forma concreta, sustentável e aplicável, uma alternativa às práticas persuasivas características do modelo unilinear, sem "demonizá-las".

Já o modelo estrutural coloca em questão "a participação do sujeito nos processos de produção de sentido, nas trocas comunicacionais" (Teixeira, 1997, p.29). Para este modelo, as trocas entre emissor e receptor não se dão apenas em uma única direção, pois o receptor transforma a mensagem ao significála. O próprio ato de recepção da mensagem demanda uma atividade de leitura e interpretação: o sentido não está inteiramente posto pela mensagem, já que depende de uma situação de leitura e de um leitor particular. Neste modelo, o receptor é considerado elemento ativo e criador de sentido, fundamental no processo de comunicação. O sentido já não é um ato unilinear e "transmissional" (Fausto Neto, 1995, p.204). 
Na discussão a seguir, procuramos analisar como os modelos de comunicação podem ser relacionados e identificados com base nas análises realizadas pelos autores dos artigos estudados. Para isso, dividimos a discussão em quatro seções, das quais as duas primeiras são mais importantes: os modelos de comunicação presentes e as representações do receptor. As duas últimas seções, sobre seleção dos conteúdos e avaliação da produção e/ou uso dos impressos, complementam as primeiras na medida em que fornecem mais informações para se respaldarem as conclusões tiradas a respeito das duas primeiras. É importante dizer que essa organização atende não apenas aos objetivos deste artigo, mas também respeita as características das publicações analisadas, uma vez que os quatro núcleos de sentido aqui destacados também foram destacados pelos autores dos artigos pesquisados, ainda que não nos mesmos termos ou de forma homogênea.

\section{Resultados e discussão}

\section{Modelos de comunicação presentes nos materiais educativos impressos}

Os trabalhos de Lefèvre (1980); Kubota et al. (1980); Rozemberg, Silva e Vasconcellos-Silva (2002); Vasconcellos-Silva, Rivera e Castiel (2003); Vasconcellos-Silva, Rivera e Rozemberg (2003); Kelly-Santos e Rozemberg, (2005); Kelly-Santos e Rozemberg, (2006); e Oliveira et al. (2007) apontam que os processos comunicativos e educativos por materiais impressos se baseiam na lógica transmissional, característica do modelo unilinear de comunicação. Podemos afirmar que tais autores encontraram, em suas pesquisas, a presença hegemônica deste modelo nos materiais educativos analisados.

Esses autores comentam que o modelo unilinear de comunicação e o discurso unidirecional restringem os espaços para negociação de sentidos, já que os sentidos seriam considerados unívocos pelos próprios produtores dos materiais. Esse modelo de comunicação filia-se ao paradigma biomédico, em que os indivíduos são vistos como carentes de informações acerca dos cuidados que devem manter para promover a boa saúde (Severo, Cunha, Ros, 2001).

Como veremos mais detalhadamente na próxima seção, a este modelo subjaz uma certa representação do sujeito-receptor: acredita-se que os indivíduos são homogêneos, como se estivessem fixados semântica e socialmente em um universo de sentidos únicos e imutáveis, e assimilassem os conteúdos dos materiais educativos da mesma forma. Kelly-Santos e Rozemberg (2005), por exemplo, comentam sobre a tendência à generalização, do público, pelos produtores de materiais, tratando-o de maneira homogênea. Neste caso, a preocupação é "distributiva", ou seja, abranger um maior número possível de pessoas, sem levar em consideração a segmentação do público. Esse posicionamento é bastante característico do modelo unilinear de comunicação, já que este supõe uma primazia do emissor sobre o receptor e a "irrelevância" das diferenciações do público, uma vez que a mensagem "bem produzida" teria a capacidade de eliminar as possíveis diferenças de leitura produzidas pelas diferenças socioculturais dos leitores (Fausto Neto, 1995).

Essa mesma tendência também foi apontada pela pesquisa de Rozemberg, Silva e Vasconcellos-Silva (2002, p.1692), que entrevistaram profissionais de um hospital para investigar o conjunto de pressupostos e estratégias de que eles se valem ao produzirem as mensagens impressas. Os autores apontaram que os produtores idealizam a mensagem como geradora de um mesmo efeito nos receptores. É como se existisse um sentido universal "adequado e correto" que pudesse ser encontrado e, então, disponibilizado aos pacientes. Consolida-se, assim, a ideia segundo a qual o grupo de leitores potenciais é homogêneo e estático.

Os autores discutem ainda que os produtores dos materiais supõem, em geral, que a doença é fruto da "ignorância" da população. Dessa forma, os materiais representam, para eles, um instrumento que pode combater essa ignorância ao difundir informações técnicas e eliminar hábitos inadequados. Os materiais educativos são considerados, portanto, recursos que possuem a tarefa de alinhar comportamentos, de inserir, na sociedade, normas e padrões de comportamentos, noções adequadas de higiene e mudanças de hábitos (Vasconcellos-Silva, Rivera, Castiel, 2003; Rozemberg, Silva, Vasconcellos-Silva, 2002). 
Pressupõe-se, também, que a disseminação/divulgação das informaç̧ões garante a adesão dos pacientes às orientações. Isto foi apontado pelo estudo de Kelly-Santos e Rozemberg (2005) quando investigaram processos comunicativos mediados por impressos no binômio saúde-trabalho sob a perspectiva dos produtores. Identificaram que o polo emissor confere a esta prática comunicativa a função de possibilitar o acesso às informações sobre os serviços de saúde e os determinantes do processo saúde-doença. Nota-se, assim, como o modelo unilinear de comunicação está "naturalizado" pelos produtores de impressos.

Esta pode ser uma das razões pelas quais a pesquisa de Vasconcellos-Silva, Rivera e Castiel (2003) encontrou uma separação entre profissionais de saúde e usuários, apesar da proximidade física que ambos os grupos precisam estabelecer nos serviços de saúde. De um lado, os profissionais transmitem informações, de forma unidirecional, sem interesse pelo diálogo, excluindo a percepção dos diversos conteúdos sociais, biográficos e culturais que influenciam essa prática. Do outro lado, estão sujeitos dotados de saberes, experiências e vivências próprias, que elaboram ativamente diversos significados diante das mensagens e que buscam auxílio para algum comprometimento. Os impressos, geralmente, não levam em consideração esta assimetria e, portanto, não favorecem a interação e o diálogo entre profissionais e população, provavelmente porque os produtores não veem sentido em tais práticas dialógicas, já que "pensam" de acordo com o modelo unilinear de comunicação. Como consequência, ocorrem "deficits" comunicativos entre a população e os profissionais e, muitas vezes, os materiais não passam de uma extensão do discurso médico hegemônico dirigido aos pacientes (Oliveira et al., 2007).

Este também é o sentido que Vasconcellos-Silva, Rivera e Castiel (2003) encontraram nos materiais impressos analisados: representam próteses comunicativas no contexto hospitalar. Ou seja, são extensões de um discurso originado em outro contexto que reforçam a assimetria e a verticalidade existentes no processo comunicativo entre profissional de saúde e paciente, como já indicado acima. É como se os impressos operassem um tipo de substituição da comunicação direta entre profissionais e pacientes, no intuito de ganhar tempo e objetividade no trabalho. Essas próteses são "como resíduos de atos de fala especialistas no formato de mensagens de natureza fragmentária, amiúde redundantes e, por vezes, contraditórias" (Vasconcellos-Silva, Rivera, Castiel, 2003, p.1668). Na visão destes profissionais-produtores, é indispensável que pacientes sigam uma regulamentação técnica que é validada em normas apoiadas em um saber complexo, pouco acessível aos leigos.

Lefèvre (1980) também discute, em relação à produção de impressos para a educação em saúde, a não-observação das referências culturais do indivíduo como forma de "invasão cultural" das próteses comunicativas. Essa foi a situação encontrada pelo autor em uma prática educativa que tentava mudar os hábitos tradicionais de populações afetadas pela esquistossomose. Nessa prática, o autor notou que a esquistossomose era considerada resultado de hábitos inadequados que deveriam ser inibidos e substituídos por novas práticas. Mas ao tentar modificar os hábitos, que são comportamentos ancorados na cultura e considerados bons, normais, naturais, os profissionais não conseguiram reduzir a incidência de esquistossomose. Comprovou-se que o desrespeito à cultura do indivíduo dificilmente permitiria alcançar a "mudança efetiva, profunda e duradoura de comportamentos" (Lefèvre, 1980, p.403).

No mesmo sentido da desconsideração sobre a cultura, a linguagem conferida aos conteúdos abordados nos materiais também é sintomática do modelo unilinear e de sua visão de "tradução" entre retórica técnico-científica e retórica popular (Teixeira, 1997). Esse processo de "tradução", no entanto, não é inequívoco, já que a linguagem adotada pode dificultar a compreensão das prescrições veiculadas. Vasconcellos-Silva, Rivera, Castiel (2003, p.1672) citam exemplos de expressões que dificultam a compreensão do discurso prescritivo presente nos impressos, que podem ser de uso corriqueiro para os profissionais, mas não fazem parte do vocabulário da população.

Da mesma forma, Oliveira et al. (2007) apontam que, quando existe uma preocupação com a adequação da linguagem, ela é orientada pela pressuposição de que a população tem deficits de cognição e dificuldades de compreensão (Oliveira et al., 2007). Rozemberg, Silva e Vasconcellos-Silva (2002) também encontraram esse tipo de orientação ao detectarem a crença segundo a qual uma "linguagem acessível" estaria em usar termos de fácil entendimento, que apenas traduzissem, para os leitores, os termos técnico-científicos. Entretanto, os autores destacam que utilizar uma linguagem adequada não significa verter para uma forma simplificada determinado conteúdo científico, mas 
compreender a linguagem e os códigos do interlocutor e atingi-lo por meio de uma expressão que faça sentido em seu universo cultural e que seja compatível com sua realidade.

A linguagem dos impressos também é marcada pela impessoalidade manifesta na preferência dada a termos técnicos em lugar de termos mais correntes. Quanto maior a complexidade na fundamentação dos argumentos acerca de instruções a serem acatadas, maior a impessoalidade dos discursos que se apresentam, geralmente, em tônicas imperativas (Vasconcellos-Silva, Rivera, Castiel, 2003).

Em contrapartida, três dos artigos analisados (Grippo, Fracolli, 2008; Ribeiro et al., 2004; Souza et al., 2003) relataram usos de impressos cujo modelo de comunicação tendia a se afastar do unilinear e a se aproximar do dialógico, como caracterizaremos a seguir.

Ribeiro et al. (2004) elaboraram materiais educativos contendo informações sobre a clínica, tratamento e prevenção da esquistossomose, no intuito de facilitar o entendimento da população sobre a doença. Por tentarem incluir o saber do outro na produção do material impresso e reduzir a dimensão de "invasão cultural" presente nas ações de saúde tradicionais, podemos considerar que a prática educativa realizada se filia, de forma predominante, aos princípios do modelo dialógico de comunicação e à base filosófica pedagógica freireana.

Já Grippo e Fracolli (2008) relatam terem produzido uma cartilha sobre desenvolvimento infantil, gestação e crescimento saudável, propondo facilitar o processo de aprendizado e promover o "empowerment" dos indivíduos. As autoras se preocuparam em utilizar uma linguagem acessível aos familiares e chamar a atenção para ações simples que, muitas vezes, eram pouco valorizadas pelos pais, mas que continham um impacto muito significativo no desenvolvimento da criança. Por utilizar instrumentos facilitadores do processo de aprendizado voltados para a realidade e contexto do indivíduo, este material educativo pode ser considerado, pelo menos em parte, como dotado de características do modelo dialógico de comunicação.

Souza et al. (2003) delinearam os passos do desenvolvimento compartilhado de um material educativo, junto com merendeiras e serventes de escolas públicas, a partir de uma investigação participativa. Neste estudo, encontravam-se, de um lado, o saber formal (as pesquisadoras), amparado pela concepção de que o sujeito pode transformar sua realidade, e, de outro, o saber da prática cotidiana (merendeiras e serventes). Os autores relatam a preocupação com a construção de um espaço de fala, em que os trabalhadores e pesquisadores puderam expor suas ideias, de maneira a superar seus preconceitos e construir coletivamente um novo sentido para suas experiências. Como resultado, elaborou-se um material informativo/educativo que socializava os conteúdos problematizados pelos trabalhadores nas oficinas em saúde. Esse processo, além de discutir os significados presentes na realidade dos indivíduos, possibilitou, segundo as autoras, a reflexão dos mesmos e o aumento de sua autonomia. As ações relatadas nesse trabalho se alinham ao modelo dialógico de comunicação.

\section{Representações do sujeito receptor nos materiais educativos}

Após analisarem os impressos, os autores Rozemberg, Silva e Vasconcellos-Silva (2002); VasconcellosSilva, Rivera e Rozemberg (2003); Vasconcellos-Silva, Rivera e Castiel (2003); e Kelly-Santos e Rozemberg (2005) observaram que os receptores/sujeitos são vistos como "consumidores" à procura de conceitos científicos diante dos materiais, pois necessitariam de entendimento para se salvaguardarem dos riscos à saúde. Rozemberg, Silva e Vasconcellos-Silva (2002, p. 1969) apontam, também, que os produtores dos materiais referem-se à clientela como "receptores passivos" dos conteúdos das mensagens transmitidas nos materiais impressos, cuja atividade intelectual seria bloqueada pela sutileza e complexidade das informações. Tais representações poderiam ser consideradas mais um indício da predominância do modelo unilinear de comunicação, já que esse modelo, como vimos, assume que o receptor se apresenta como uma clientela "passiva", de "saber vazio" a ser preenchido ou corrigido por saberes científicos.

Oliveira et al. (2007) apontam que, na opinião dos profissionais de saúde, a clientela apresenta deficits cognitivos que, somados à precariedade da situação econômica e pelos baixos níveis de escolaridade, representam empecilhos ao bom entendimento das mensagens dos materiais educativos. Os autores usam, como exemplo, uma frase dita por um profissional: "O QI do povo ainda é muito baixo" (Oliveira et al., 2007, p.291). 
As autoras Kelly-Santos e Rozemberg (2006, p.980) relataram, explicitamente, a "condição de assujeitamento, via 'desqualificação' e 'desvalorização' do saber da clientela", ao estudarem as relações de produção do binômio saúde-trabalho. Ao investigarem a prática comunicativa por impressos em curso nos Programas de Saúde do Trabalhador, essas autoras evidenciaram que o saber operário é totalmente desacreditado. Predomina o ponto de vista do especialista, em detrimento dos saberes do público a que se destina, como acontece no modelo unilinear de comunicação.

Em um caso extremo, pacientes analfabetos foram comparados a crianças pequenas, evidenciando como o profissional de saúde pode "infantilizar" o adulto sem escolaridade. A comparação com uma criança tem um peso significativo, já que, segundo essa visão, o indivíduo sem escolaridade precisaria aprender tudo sobre o mundo, como se fosse uma criança de saber vazio que precisa ter o mundo desvelado por um adulto (Rozemberg, Silva, Vasconcellos-Silva, 2002).

Essa "infantilização" do paciente é confirmada pelo estudo de Vasconcellos-Silva, Rivera e Castiel (2003), que, ao analisarem imagens em impressos, apontam que é muito frequente o uso de personagens de quadrinhos nos impressos utilizados em câncer e pediatria. Esses materiais procuram "amenizar" os conteúdos, já que circulam em contextos de sofrimento e dor, mas acabam utilizando um estilo textual e gráfico que simplifica excessivamente as informações. Consequentemente, pode-se concluir que os destinatários são subestimados e compreendidos como sujeitos incapazes de dialogar em condições de igualdade, reforçando a lógica transmissional do modelo unilinear de comunicação que caracteriza tais materiais.

Também criticando esse modelo, a pesquisa de Lefèvre (1980, p.403) aponta que os sujeitos são vistos como "ignorantes" pelos profissionais de saúde, pois possuem hábitos "primitivos" que causam doenças e, por isso, deveriam ser substituídos por hábitos "modernos", por meio da difusão de informações.

\section{Seleção de conteúdo para os materiais}

De acordo com os autores Lefèvre (1980); Kubota et al. (1980); Rozemberg, Silva e VasconcellosSilva (2002); Vasconcellos-Silva, Rivera e Rozemberg (2003); Vasconcellos-Silva, Rivera e Castiel (2003); Kelly-Santos e Rozemberg (2005); Kelly-Santos e Rozemberg (2006); e Oliveira et al. (2007), a seleção do conteúdo dos impressos é feita pelos próprios profissionais de saúde. Nas pesquisas desses autores, quando os profissionais entrevistados foram perguntados sobre como os conteúdos são selecionados, verificou-se que essa seleção não aparece como objeto de problematização. A inclusão dos grupos de pacientes no processo de elaboração de impressos raramente ocorre. Por este motivo, pode-se considerar que a contribuição e/ou interferência que estes grupos poderiam ter sobre a seleção dos conteúdos é pouco usual. Tal fato denota um desinteresse do produtor desse tipo de impresso pelo diálogo com os seus receptores.

Rozemberg, Silva e Vasconcellos-Silva (2002) comentam que os profissionais se baseiam em manuais técnicos e, sobretudo, na própria experiência do atendimento para definirem as informações consideradas importantes. Dessa forma, são contemplados, nos materiais, algumas dúvidas e questionamentos mais comuns da clientela sobre problemas específicos, muitas vezes usando-se o formato de "perguntas e respostas" para proporcionar uma leitura dinâmica do material. A este respeito, o estudo de Vasconcellos-Silva, Rivera e Castiel (2003, p.1677) afirma que, apesar de ser útil abordar as dúvidas mais frequentes da clientela, esta estratégia pode resultar na valorização de questões que não são importantes para os clientes e na desvalorização daquelas que o são.

Vasconcellos-Silva, Rivera e Rozemberg (2003) ressaltam que os profissionais da área da educação em saúde confundem, sistematicamente, as dimensões comunicacionais - que envolvem interação humana - com as transmissionais - que envolvem tecnologia da informação. Por isso, recomendam que os interesses dos participantes e a experiência de cada um deva orientar a seleção dos conteúdos, promovendo a construção compartilhada de conhecimentos pelo diálogo (Ribeiro et al., 2004). Souza et al. (2003) também referem que é necessário que os sujeitos participem ativamente da seleção dos conteúdos dos materiais, pois o ponto de partida para a produção de novos conhecimentos é a experiência e a cultura dos sujeitos envolvidos, buscando um espaço de aprendizagem coletiva. 
Somente os autores Rozemberg, Silva e Vasconcellos-Silva (2002); Souza et al. (2003); Ribeiro et al. (2004); e Grippo e Fracoli (2008) descreveram o uso de impressos em que a seleção de conteúdos ocorreu em meio ao diálogo com os sujeitos sobre suas experiências e necessidades. Ribeiro et al. (2004), por exemplo, elaboraram impressos com a proposta de atenderem as necessidades educativas da população. Tendo em vista o índice de analfabetismo e o baixo nível de escolaridade, os autores selecionaram os assuntos a serem abordados partindo dos interesses e experiências dos participantes, estimulando a troca de experiências.

O estudo de Rozemberg, Silva e Vasconcellos-Silva (2002) apontou a inexistência de pesquisas prévias para a seleção de conteúdo dos impressos. Esses autores acreditam que, ao não se realizarem pesquisas, resultam simplificações, generalizações e reducionismos, porque os conteúdos passam a se referir ao que os profissionais acreditam que "o paciente quer". De acordo com esses autores, os únicos estudos prévios à produção, apontados na literatura, restringem-se ao conhecimento do nível de escolaridade do público, como se esta informação fosse suficiente para traçar um perfil consistente dele. $\mathrm{Na}$ verdade, desta forma, reforçam-se estereótipos sobre a baixa escolaridade.

\section{Avaliação da produção e/ou uso dos materiais}

Kubota et al. (1980) referem que é fundamental avaliar o resultado do uso dos materiais educativos para conhecer o papel que esses materiais efetivamente desempenham na comunicação entre profissionais e usuários dos serviços de saúde. De acordo com Kelly-Santos e Rozemberg (2005), a ausência de experiências que avaliem os materiais educativos se contrapõe à quantidade de impressos que são utilizados. São precárias as referências que pesquisam sobre a eficiência ou comunicabilidade dos materiais educativos.

De acordo com Kubota et al. (1980), existem dois procedimentos de avaliação que podem ser considerados para o material impresso: um pré-teste aplicado durante o processo de produção, para se conhecer a percepção e interpretação das informações pelos sujeitos receptores; e uma avaliação da eficiência durante o seu uso, destinada a analisar o comportamento dos indivíduos em relação ao material.

Rozemberg, Silva e Vasconcellos-Silva (2002, p.1686) apontam que a avaliação do material educativo, quando ocorre, raramente escapa do enfoque quantitativo e mecanicista das "escalas de atitudes e opiniões", ou oferece resultados já mais ou menos previstos, como os exemplos que os autores citam: "o público está sensibilizado...", "os pacientes agora sabem melhor", ou "aprendeu um pouquinho mais sobre a doença". Estas supostas avaliações nada esclarecem sobre as estratégias e experiências de apropriação das mensagens por parte dos usuários. Para os autores, é importante conhecer as racionalidades, motivações, lógicas de utilização e sentido das mensagens informativas/ educativas, no universo do público ao qual são endereçadas.

Kelly-Santos e Rozemberg $(2006$, p.983) consideram a análise dos materiais educativos, por seus próprios destinatários, como um lugar privilegiado de negociação de sentidos e, sobretudo, um espaço de apreensão dos modos de viver de diferentes grupos sociais. "Dessa forma, os materiais educativos em saúde são componentes do processo de aprendizagem, e quando usados de maneira participativa e interativa podem facilitar a produção de conhecimento por seus leitores".

Oliveira et al. (2007) também defendem a participação ativa dos sujeitos nos processos de desenvolvimento dos materiais e na avaliação dos mesmos, já que isto seria parte de uma abordagem que coloca os materiais a serviço da autonomia do paciente no cuidado. Tal ação caracterizaria os modelos de comunicação dialógico e estrutural, pouco encontrados, no entanto, nas pesquisas analisadas.

Rozemberg, Silva, Vasconcellos-Silva (2002) afirmam que, como o objetivo da maioria dos impressos é o convencimento unilateral, com poucas oportunidades de interação com a clientela, a potencialidade do uso desse tipo de material é restrita, já que esses não "falam realmente" com os pacientes. Da mesma forma, os autores Grippo e Fracolli (2008) ressaltam a necessidade de os sujeitos receptores serem ouvidos na construção dos materiais, na utilização e avaliação destes. Para esses autores, quando os indivíduos são levados em consideração na avaliação dos materiais, há melhor chance de que a 
educação em saúde por impressos se transforme em uma experiência rica e aumente a identificação dos sujeitos com o material educativo.

Kubota et al. (1980) referem-se ao uso de materiais educativos como algo que deve ser complementado por outras práticas educativas, pois esses materiais não podem ser considerados como fins em si mesmos. Deve-se, sempre, complementar a distribuição do material com orientações sobre seu conteúdo. A educação em saúde representa um processo, portanto, utilizar somente um material educativo não garante bons resultados. Qualquer material educativo utilizado isoladamente resultará na pouca validade para a ação educativa.

\section{Conclusão}

Como pudemos notar a partir da análise dos artigos levantados por esta pesquisa, na maior parte das vezes, o uso de materiais impressos na educação em saúde é descrito de forma crítica e caracterizado como deficiente e/ou de alcance ou eficácia limitada. Da mesma forma, podemos afirmar que esses materiais estão quase sempre fundamentados por um mesmo modelo de comunicação (o modelo unilinear) e uma mesma visão estereotipada da clientela, além de carecerem de processos mais ampliados de seleção dos conteúdos e de avaliação. Tais conclusões parecem estar relacionadas. Seria preciso pesquisar melhor como esta relação se dá.

No que diz respeito aos modelos de comunicação encontrados, vimos que, de acordo com o universo pesquisado, o modelo unilinear de comunicação predomina nos materiais impressos para educação em saúde. Esse modelo está naturalizado entre produtores e profissionais de saúde, e a clientela é vista, quase sempre, como um todo homogêneo. A separação entre profissionais de saúde e usuários do sistema está claramente indicada pela forma como os impressos funcionam, como "próteses" ou extensões do discurso médico hegemônico, que reforçam a "invasão cultural" presente, de forma predominante, nas ações de saúde. A linguagem dos impressos é tratada, geralmente, como mero instrumento de "tradução" entre o científico e o popular. Apesar de as interações ativas entre profissional e clientela serem valorizadas nos estudos analisados, como forma de alcançar resultados mais positivos, a predominância do modelo unilinear de comunicação parece limitar este tipo de ação. Poucos artigos relataram perspectivas de produção de impressos caracterizadas pelo modelo dialógico e nenhum pelo modelo estrutural de comunicação.

No que diz respeito às representações mais frequentes do sujeito receptor (clientela dos impressos), esses são vistos como "consumidores" de informação, passivos, ignorantes e/ou deficitários no que diz respeito às capacidades cognitivas, à inteligência e ao uso da língua. A infantilização da clientela é o resultado mais frequente desta representação. A "homogeneização" da clientela, característica do modelo unilinear, também encontra repercussões nas representações e reforça os laços entre elas e o modelo de comunicação adotado pelo produtor/profissional de saúde.

Já no que diz respeito à seleção de conteúdo, esta é feita, predominantemente, pelos profissionais de saúde envolvidos na produção do impresso, a partir de manuais técnicos e/ou de suas experiências profissionais. Essa seleção não é problematizada pelos produtores. São raras as pesquisas prévias e a participação de usuários na seleção dos conteúdos. Quanto à avaliação dos materiais, quando encontrada, se apresenta de forma inconsistente, assistemática e com pequena participação dos sujeitos receptores.

Este panorama aponta para a predominância do modelo biomédico na prática educativa em saúde por impressos, em que o sujeito é impotente na relação estabelecida com os profissionais da área - o que distancia ainda mais o saber científico do popular.

Entre as principais recomendações dos autores dos artigos analisados, podemos destacar, como as mais frequentes: a consideração da cultura e do saber dos receptores na produção de materiais impressos, e a criação de espaços para reflexão e compartilhamento de conhecimentos entre profissionais e clientela (Grippo, Fracolli, 2008; Rozemberg, Silva, Vasconcellos-Silva, 2002). Desta perspectiva, uma outra representação da clientela ganha força: o sujeito receptor é um ser dotado de saber e de razão, cujos conhecimentos e experiências devem ser valorizados, e não subestimados, 
como afirmam Kubota et al. (1980), Souza et al. (2003), Ribeiro et al. (2004), Grippo e Fracolli (2008), por exemplo. Vasconcellos-Silva, Rivera e Rozemberg (2003) reforçam essa visão ao reafirmarem a importância do estabelecimento de relações interpessoais baseadas em regras de reconhecimento mútuo para a negociação de sentidos, que garantam o questionamento e uma escuta ativa.

Podemos, assim, afirmar que é predominante, na perspectiva teórico-crítica adotada pelos artigos analisados, o entendimento segundo o qual a clientela é potencialmente criativa e sensível, e que o processo de educar-cuidar deve ocorrer em uma relação horizontal, dialógica, recíproca e humana.

A partir destas conclusões, podemos inferir que as análises realizadas nos artigos pesquisados são marcadas por um conflito de perspectivas entre os analistas dos materiais impressos e os produtores dos materiais. Os analistas, ou seja, os autores dos artigos aqui descritos, filiam-se, claramente, a uma perspectiva de inspiração freireana e, portanto, ao modelo dialógico de comunicação, enquanto os produtores de materiais impressos, de acordo com as análises encontradas nesta pesquisa, se alinhariam, mais frequentemente, ao modelo unilinear hegemônico de comunicação. Tal conflito fica claro nas recomendações dadas pelos artigos, quase sempre questionando as ações comunicativas tradicionais e hegemônicas. Os trabalhos que propuseram experiências educativas "alternativas" a essas ações hegemônicas, por sua vez, não relatam as dificuldades apontadas pelo referencial de análise aqui adotado, o que não nos permite avaliar a sua viabilidade como prática contra-hegemônica.

De nossa parte, acreditamos que, apesar do olhar eminentemente crítico da pesquisa na área, a comunicação e a educação por materiais impressos podem ainda abrir caminhos novos para a promoção da saúde, seja pela participação da população numa construção compartilhada de conhecimentos (conforme os modelos dialógico e estrutural), seja por outros meios que venham a ser implementados (Teixeira, 1997). No entanto, se aceitarmos que o receptor de materiais educativos tem papel ativo na produção de significado, devemos atentar não só para a melhoria da produção desses materiais, mas também para a pesquisa sobre a sua recepção/consumo. Portanto, a consideração sobre o papel do receptor/cliente na recepção de materiais educativos em saúde deve estar refletida não só na produção de novos materiais, mas também na pesquisa sobre como os processos de recepção e mediação se dão efetivamente.

\section{Colaboradores}

Os autores trabalharam juntos em todas as etapas de produção do manuscrito.

\section{Referências}

ARAÚJO, I.S. Materiais educativos e produção dos sentidos na intervenção social. In: MONTEIRO, S.; VARGAS, E.P. (Org.). Educação, comunicação e tecnologia: interfaces com o campo da saúde. Rio de Janeiro: Editora Fiocruz, 2006. p.49-69.

ASSIS, M. Da hipertensão à vida: por uma práxis comunicativa na educação e saúde. 1992. Dissertação (Mestrado) - Instituto de Medicina Social, Universidade do Estado do Rio de Janeiro, Rio de Janeiro. 1992.

FAUSTO NETO, A. A deflagração do sentido: estratégias de produção e de captura da recepção. In: SOUZA, M. (Org.). Sujeito, o lado oculto do receptor. São Paulo: Brasiliense, 1995. p.181-217.

FREIRE, P. Pedagogia do oprimido. Rio de Janeiro: Paz e Terra, 1994.

Extensão ou comunicação? Rio de Janeiro: Paz e Terra, 1983. 
FREITAS, F.V. Leitura de materiais educativos usados na educação em diabetes: uma análise por meio da semiótica social. 2009. Dissertação (Mestrado em Educação em Ciências e Saúde) - Núcleo de Tecnologia Educacional para a Saúde, Universidade Federal do Rio de Janeiro, Rio de Janeiro. 2009.

GRIPPO, M.L.V.S.; FRACOLLI, L.A. Avaliação de uma cartilha educativa de promoção ao cuidado da criança a partir da percepção da família sobre temas de saúde e cidadania. Rev. Esc. Enferm. USP, v.42, n.3, p.430-6, 2008. Disponível em: <http:// www.scielo.br/pdf/reeusp/v42n3/v42n3a02.pdf>. Acesso em: 30 mai. 2009.

KELLY-SANTOS, A. A palavra \& as coisas: produção e recepção de materiais educativos sobre hanseníase. 2009. Tese (Doutorado) - Escola Nacional de Saúde Pública Sérgio Arouca, Fundação Oswaldo Cruz, Rio de Janeiro. 2009.

KELLY-SANTOS, A.; ROZEMBERG, B. Estudo de recepção de impressos por trabalhadores da construção civil: um debate das relações entre saúde e trabalho. Cad. Saude Publica, v.22, n.5, p.975-85, 2006. Disponível em: <http://www.scielo.br/pdf/ csp/v22n5/10.pdf>. Acesso em: 30 mai. 2009.

Comunicação por impressos na saúde do trabalhador: a perspectiva das instâncias públicas. Cienc. Saude Colet., v.10, n.4, p.929-38, 2005. Disponível em: $<$ http://www.scielo.br/scielo.php?script=sci_arttext\&pid=\$1413$81232005000400016 \& \operatorname{lng}=p t \& n r m=$ iso $>$. Acesso em: 30 mai. 2009.

KUBOTA, N. et al. Avaliação de material educativo: adequação de quatro volantes sobre alimentação da criança de 0 a 12 meses de idade. Rev. Saude Publica, v.14, n.1, p.101-22, 1980. Disponível em: <http://www.scielo.br/ scielo.php?script=sci_arttext\&pid=S0034-89101980000100009>. Acesso em: 30 mai. 2009.

LEFÈVRE, F. Análise de cartazes sobre esquistossomose elaborados por escolares. Rev. Saude Publica, v.14, n.3, p.396-403, 1980. Disponível em: <http://www.scielo.br/pdf/ rsp/v14n3/10.pdf>. Acesso em: 30 mai. 2009.

MONTEIRO, S.; VARGAS, E.P. (Orgs.). Educação, comunicação e tecnologia: interfaces com o campo da saúde. Rio de Janeiro: Editora Fiocruz, 2006.

OLIVEIRA, V.L.B. et al. Modelo explicativo popular e profissional das mensagens de cartazes utilizados nas campanhas de saúde. Texto Contexto Enferm., v.16, n.2, p.287-93, 2007. Disponível em: <http://www.scielo.br/pdf/rsp/v14n3/10.pdf>. Acesso em: 30 mai. 2009.

RIBEIRO, P.J. et al. Programa educativo em esquistossomose: modelo de abordagem metodológica. Rev. Saude Publica, v.38, n.3, p.415-21, 2004. Disponível em: <http://www.scielo.br/pdf/rsp/v38n3/20659.pdf>. Acesso em: 30 mai. 2009.

ROZEMBERG, B.; SILVA, A.P.P.; VASCONCELLOS-SILVA, P.R. Impressos hospitalares e a dinâmica de construção de seus sentidos: o ponto de vista dos profissionais de saúde. Cad. Saude Publica, v.18, n.6, p.1685-94, 2002. Disponível em: <http://www.scielo.br/pdf/csp/v18n6/13265.pdf>. Acesso em: 30 mai. 2009.

SANTOS, J.; WESTPHAL, M. Práticas emergentes de um novo paradigma de saúde: o papel da universidade. Est. Avançad., v.13, n.35, p.71-88, 1999.

SEVERO, D.O.; CUNHA, A.P.; ROS, M.A. Articulação nacional de movimentos e práticas de educação popular e saúde no estado de Santa Catarina: fortalezas e fragilidades. Texto Contexto Enferm., v.16, n.2, p.239-45, 2001.

SOUZA, K.R. et al. O desenvolvimento compartilhado de impressos como estratégia de educação em saúde junto a trabalhadores de escolas da rede pública do Estado do Rio de Janeiro. Cad. Saude Publica, v.19, n.2, p.495-504, 2003. Disponível em:

<http://www.scielo.br/pdf/csp/v19n2/15415.pdf>. Acesso em: 30 mai. 2009. 
TEIXEIRA, R.R. Modelos comunicacionais e práticas de saúde. Interface - Comunic., Saude, Educ., v.1, n.1, p.7-40, 1997.

VASCONCELLOS-SILVA, P.R.; RIVERA, F.J.U.; CASTIEL, L.D. Comunicação instrumental, diretiva e afetiva em impressos hospitalares. Cad. Saúde Pública, v.19, n.6, p.1667-79, 2003. Disponível em: <http://www.scielo.br/pdf/csp/v19n6/a11v19n6.pdf>. Acesso em: 30 mai. 2009.

VASCONCELLOS-SILVA, P.R.; RIVERA, F.J.U.; ROZEMBERG, B. Próteses de comunicação e alinhamento comportamental sobre impressos hospitalares. Rev. Saude Publica, v.37, n.4, p.531-42, 2003. Disponível em: <http://www.scielo.br/pdf/rsp/v37n4/ 16791.pdf>. Acesso em: 30 mai. 2009.

FREITAS, F.V.; REZENDE FILHO, L.A. Modelos de comunicación y uso de impresos en educación en salud: una pesquisa bibliográfica. Interface - Comunic., Saude, Educ., v.15, n.36, p.243-55, jan./mar. 2011.

El artículo presenta los resultados de una encuesta sobre el uso de materiales impresos en la educación en la salud, con enfoque sobre los modelos de comunicación, las representaciones de los usuarios y las dinámicas de selección de contenidos y de avaliación. Se realizó un análisis de 11 artículos de búsquedas en la base SciELO. En este análisis, los artículos indican que la comunicación se caracteriza por el modelo unilinear y la impersonalidad. Los receptores son considerados meros consumidores de conceptos científicos. En la mayoría de los casos, el profesional de la salud es el único responsable de la selección de contenido. En los artículos pesquisados se encuentra un conflicto entre la perspectiva de sus autores (dialógica) y la de los productores de los impresos (unilinear).

Palabras clave: Educación para la salud. Comunicación. Modelos de comunicación. Representaciones. Materiales educativos y de divulgación. Material impreso. 